\title{
EM QUE CONSISTE A IDENTIDADE LINGUÍSTICA? UMA QUESTÃO SAUSSURIANA
} Maria Fausta Pereira de Castro*

(iD) https://orcid.org/0000-0003-1420-6096

Como citar este artigo: PEREIRA DE CASTRO, M. F. Em que consiste a identidade linguística? Uma questão saussuriana. Todas as Letras - Revista de Lingua e Literatura, São Paulo, v. 22, n. 2, p. 1-12, maio/ago. 2020. DOI 10.5935/1980-6914/eLETDO 2013432

Submissão: maio de 2020. Aceite: julho de 2020.

Resumo: Este trabalho propõe uma reflexão sobre o conceito saussuriano de identidade linguística. O Índice Analítico do Curso de Linguística Geral (2018 [1916]) nos mostra que o termo identidade recebe apenas duas entradas: um capítulo sobre a identidade sincrônica e outro sobre identidade diacrônica, mas esses dois tópicos abrem um universo de grande alcance teórico. Com o auxílio de outras fontes de consulta, nosso objetivo é refletir sobre os caminhos apontados por Saussure para o enfrentamento do problema da identidade linguística, isto é, a questão do ponto de vista que a define e a consideração de um tipo de entidade que rompe com a tradição filosófica.

Palavras-chave: Identidade. Diferença. Valor. Ponto de vista. Sincronia/diacronia. 


\section{A IDENTIDade Linguística ${ }^{1}$}

O tema da identidade linguística está presente em vários momentos da reflexão de Saussure: no Curso de Linguística Geral (2018 [1916])² e suas edições críticas - por Engler (SAUSSURE, 1989 [1968]) e De Mauro (SAUSSURE, 2005 [1967]) -, nos cursos II (1908-1909) e III (1910-1911), oferecidos por Saussure na Universidade de Genebra, com notas dos alunos e cujos cadernos foram posteriormente publicados e, ainda, em manuscritos que se encontram arquivados na Biblioteca de Genebra (BGE) e que serão mencionados ao longo deste trabalho.

Essa apresentação, em nada exaustiva, apenas oferece uma primeira medida do espraiamento do tema da identidade ao longo dos textos saussurianos e dos cursos.

Para Saussure (2004, p. 34) a identidade é a base necessária e absoluta para o trabalho do linguista: "[...] é só por ela e com relação a ela que se chega a determinar, depois, as entidades de cada ordem, os termos primeiros que o linguista pode, legitimamente, acreditar ter diante de si".

A anterioridade lógica atribuída à identidade e seu consequente papel na constituição das entidades linguísticas podem esclarecer, pelo menos em parte, o fato de Saussure atribuir à questão um alcance filosófico, termo pouco usado por ele. Em outras palavras, podemos nos perguntar com o titulo deste trabalho e adiantando o que leremos no próprio Saussure: em que consiste a identidade de um signo em um sistema semiológico?

Trazemos aqui um excerto do manuscrito Ms. fr. 3951, fol. 1v (SAUSSURE, 1894), também nomeado por alguns pesquisadores como "Notas para um artigo sobre Whitney" (cf. GODEL, 1969, p. 43). A folha em questão (1v) se abre em duas páginas do caderno. Como se pode ver, à esquerda uma página quase em branco, em que podemos ler no alto uma frase em diagonal: "x ou uma convenção inicial". Mais abaixo - ainda em diagonal -, um borrão ilegivel com uma escrita em espelho, provavelmente marca de tinta da página ao lado.

$\mathrm{Na}$ página à direita e na sua margem esquerda, está marcado outro x. Seguindo um critério do próprio Saussure, inserimos o trecho da página anterior sobrescrito na linha assinalada. Segue então o texto objeto de nossa atenção: 
Figura 1 - Excerto do manuscrito Ms. fr. 3951

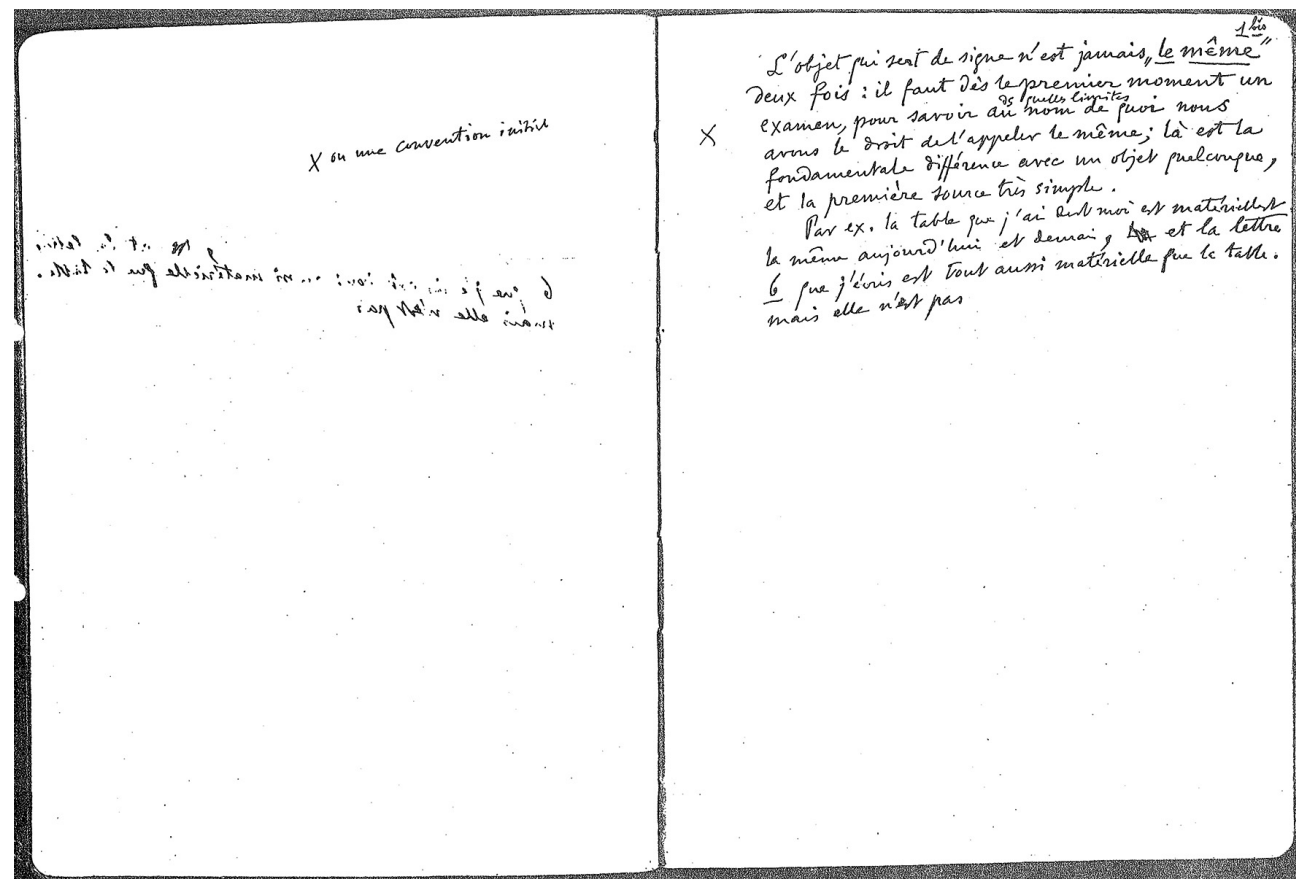

O objeto que serve de signo não é jamais o mesmo duas vezes: é preciso desde o primeiro momento um exame, ou uma convenção inicial para saber dentro de quais limites em nome do que temos o direito de chamá-lo o mesmo; é essa a diferença fundamental com um objeto qualquer, e a primeira fonte muito simples.

Por ex., a mesa que tenho diante de mim é materialmente a mesma hoje e amanhã, $x x^{3}$ e a letra $\underline{b}$ que escrevo é tão material como a mesa. mas $^{4}$ ela não é [ ] ${ }^{5}$

Fonte: Genève, Bibliothèque de Genève, Ms. fr. 3951, fol. 1v.

Este é o início de um trabalho que começou a ser escrito porque Saussure fora encarregado de escrever o obituário de Whitney, morto em 1894. Mas até um obituário se transformou em um texto teórico; teórico demais para o seu primeiro objetivo e Saussure desiste da tarefa, já que suas elaborações se encaminhariam para uma crítica a certos pontos de vista do colega.

A nota condensa várias questões presentes também em outros momentos da reflexão do genebrino, como por exemplo, nos cursos II e III, como assinalou Godel (1969, p. 136), e no próprio CLG. Saussure abre o texto tratando da questão da identidade pela formulação de um axioma: "O objeto que serve de signo não é jamais o mesmo duas vezes" e, para ilustrá-lo, toma como exemplo um par de objetos - a mesa que está diante dele e uma letra do alfabeto, a letra $\underline{b}$; a mesa é materialmente a mesma de um dia para o outro, e a letra $\underline{b}$, "tão material como a mesa, mas ela não é [ ]"; surge o branco, o silêncio, nenhuma pontuação.

\footnotetext{
3 Esta sequência de dois ou mais xx indica um trecho ilegível e tachado pelo autor.

4 Em letra minúscula no manuscrito.

5 Os colchetes vazios indicam um branco; nada escrito e nenhuma pontuação.
} 
Turra (2018, p. 173-174) ${ }^{6}$ arremata assim esse trecho:

Corte onde suporíamos um "a mesma hoje e amanhã" [...]. Saussure busca estabelecer uma relação entre identidade e materialidade, o que funciona para a mesa. Ao propor uma analogia com a letra $\mathrm{b}$, a fim de evidenciar a radical diferença entre um objeto "no mundo" e o signo de um sistema semiológico, o impasse se estabelece e se mostra no branco da página.

E a seguir estende sua reflexão, insistindo na especificidade do signo: há algo na letra que é "tão material quanto a mesa", mas por outro lado há "algo de material' que se inscreve 'no jogo da língua', fazendo com que sua identidade não seja estabelecida isoladamente” (TURRA, 2018, p. 174).

No jogo da língua, está também outra questão: Saussure não deixa mencionar no manuscrito um problema que tem amplo desenvolvimento no decorrer da sua teorização, isto é, a noção de ponto de vista: é preciso determinar com que critérios, dentro de quais limites, de que ponto de vista se tem o direito de considerar um objeto que serve de signo, isto é, que está no sistema da língua, como "o mesmo". A asserção saussuriana a esse respeito é abrangente e diz respeito tanto à sincronia como à diacronia, à oralidade e à escrita.

Entre tantas outras passagens em que Saussure discute fatos que dizem respeito à identidade, é a partir de um fato sincrônico, relatado no CLG, que o citamos a seguir. O problema foi tratado no decorrer dos cursos II e III: a identidade da palavra "Senhores" e suas diversas ocorrências em uma conferência. É algo na corrente da fala que está em questão.

Quando, numa conferência, ouvimos repetir diversas vezes a palavra Senhores! temos o sentimento de que se trata, toda vez, da mesma expressão, e, no entanto, as variações do volume de sopro e da entonação a apresentam, nas diversas passagens, com diferenças fônicas assaz apreciáveis - tão apreciáveis como as que servem, aliás, para distinguir palavras diferentes ( $c f$. fr. pomme, "maçã", e paume, "palma", goute, "gota", e je goute "eu gosto", fuir, "fugir" $e$ fouir "cavar" etc.); ademais, esse sentimento de identidade persiste, se bem que do ponto de vista semântico não haja tampouco identidade absoluta entre um Senhores! e outro, da mesma maneira por que uma palavra pode exprimir ideias bastante diferentes sem que sua identidade fique seriamente comprometida (cf. "adotar uma moda" e adotar uma criança", a flor da macieira e "a flor da nobreza etc.).

O mecanismo linguístico gira todo ele sobre identidades e diferenças, não sendo estas mais que a contraparte daquelas (SAUSSURE, 2018 [1916], p. 153-154).

Trata-se aqui de um fenômeno diverso daquele discutido a partir do manuscrito. Se lá o impasse se estabelece e surge o branco na escrita, aqui o texto ganha até mesmo contornos didáticos - inseridos pelos editores -, como se pode constatar ao ler a edição crítica de Engler (SAUSSURE, 1989 [1968], p. 243-verso) e compará-la com o texto do CLG.

As observações acrescentadas são de interesse; as variações de sopro, entonação ou mesmo do ponto de vista semântico não impedem o sentimento de identidade. Os exemplos são significativos tanto mais porque tocam também em 
um ponto caro a Saussure, isto é, a relação entre sentido próprio e sentido figurado. Para ele, "não há diferença entre o sentido próprio e o sentido figurado das palavras - porque o sentido das palavras é uma coisa essencialmente negativa" (SAUSSURE, 2004, p. 73).

Entende-se assim o modo como a citação é fechada, dando destaque ao jogo de contrapartes que caracteriza o mecanismo da língua: "O mecanismo linguístico gira $[\ldots] "$ ".

O capítulo III da segunda parte do CLG - "Identidades, realidades, valores" - é objeto de inúmeros comentários por parte de De Mauro na sua edição crítica (SAUSSURE, 2005 [1967]).

Atento ao que os alunos registraram em notas do início do curso $\mathrm{II}^{8}$, De Mauro observa que Saussure trata do problema da identidade, tanto do ponto de vista das questões relativas à diacronia como à sincronia (cf. SAUSSURE, 2005 [1967]).

$\mathrm{Na}$ essência, trata-se "das razões que permitem identificar dois fatos como duas manifestações de uma coisa que permanece idêntica" (cf. SAUSSURE, 2005, p. 459). O problema se impôs a Saussure, enquanto um linguista do século XIX, "nos seus termos diacrônicos: o que permite identificar o francês chaud ao latim calidus?" (p. 460). Entretanto, por decisão dos editores, essa questão e a discussão que a ela se refere foram levadas para o capitulo VIII ${ }^{9}$, quando na verdade Saussure tratou-as "em relação com a questão mais radical da identidade sincrônica ${ }^{10}$, reduzindo o problema diacrônico ao sincrônico" (p. 460). Essa crítica pode, aliás, ser confirmada pelo o que lemos no próprio capítulo VIII, que é concluído convergindo para o que diz De Mauro.

"Ora, a identidade diacrônica de duas palavras tão diferentes quanto calidum e chaud significa simplesmente que se passou de uma a outra por meio de uma série de identidades sincrônicas na fala, sem que jamais o vínculo que as une tenha sido rompido pelas transformações fonéticas sucessivas” [...] Eis porque pudemos dizer, nas páginas 153-154, que é tão interessante saber como Senhores! repetido diversas vezes em seguida num discurso é idêntico a si mesmo, quanto saber por que, em francês, pas (negação) é idêntico a pas (substantivo) ou, o que vem a dar na mesma, por que chaud é idêntico a calidum. O segundo problema não é, com efeito, mais que um prolongamento e uma complicação do primeiro (SAUSSURE, 2005 [1967], p. 250).

O alcance teórico e epistemológico do capítulo III é mais uma vez comentado por De Mauro na breve citação a seguir. Momento em que Saussure interroga as categorizações vigentes na linguística. Unde exoriar? ${ }^{11}$, pergunta-se ainda em outro momento de sua reflexão.

Neste capítulo igualmente, a intenção de Saussure é destruens ${ }^{12}$, tendendo a lançar dúvida sobre o conjunto das categorizações e das definições de base ontológico-universalista que as gramáticas modernas herdaram da tradição aristotélico-racionalista (SAUSSURE, 2005 [1916], p. 460). 
Saussure caminha em direção a um procedimento de desnaturalização da distinção entre as palavras, entre as partes do discurso: substantivos, verbos, adjetivos etc. são postos sob a sombra da dúvida. A distinção entre eles não é tomada como uma "realidade linguística inegável [...]: e se forem fantasmas, que realidade opor-lhes?” (SAUSSURE, 2018 [1916], p. 156).

A pergunta não cai no silêncio: para escapar às ilusões, diz ele, é preciso partir da premissa de que as "entidades concretas da lingua" não se mostram por si mesmas. Mas se procurarmos apreendê-las "tomaremos contato com o real"; a base para as classificações de que precisa a linguística para pensar o seu campo.

Com a menção ao valor linguístico, Saussure (2018 [1916], p. 156) parece elaborar uma síntese do que disse, das formulações apresentadas, dos conceitos com que trabalhou e tudo se resume a "valor": "Por fim todas as noções versadas não diferem daquilo chamamos valores".

A equiparação entre valor e tantos outros termos da teorização saussuriana estava também presente em aula do curso II, como nota Riedlinger:

Voltamos a um ponto que <já> abordamos. Para simplificar, M. de Saussure não faz diferença fundamental entre <essas cinco coisas >: um valor, uma identidade, uma unidade, uma realidade (no sentido linguístico, realidade linguística) $e$ um elemento concreto linguístico (cf. SAUSSURE, 1997, p. 29).

O que está em questão é uma relação entre elementos de um sistema; se isolamos este ou aquele não significa que os outros estejam fora do jogo das identidades e das diferenças. Falar de unidade e identidade é, nesse sentido, também falar de valor.

\section{Ponto de vista, IDentidade E DiferençA}

No contexto epistemológico reinante 80 anos depois da publicação do Curso de Linguística Geral, foi encontrada em 1996, na estufa da casa da família Saussure em Genebra, uma mala com vários documentos familiares, entre os quais, manuscritos do próprio Saussure. Esses últimos foram doados à Biblioteca de Genebra, arquivados e catalogados por Rudolf Engler sob a cota "Arch. de Saussure 372".

Ainda que o tempo tenha passado, o material encontrado mantinha certa ordem: envolvidos por um papel de embalagem, em que Saussure escreveu Science du langage, estavam 12 envelopes e em cada um alternavam-se os titulos: ora "De l'essence double / à remarquer", ora "De l'essence double" ou ainda "De la double essence du (langage)"13.

Apesar do grande interesse do material, Saussure dá mostra de considerar os fragmentos do Essence Double como um projeto de "opúsculo" de linguística geral (cf. BÉGUELIN, 2016), que ele começou a elaborar a partir de 1891.

Já em 1997, Engler lança a primeira publicação de um excerto do arquivo nos Cahiers Ferdinand de Saussure (CFS), n. 50. É parte das "Notas pessoais de Ferdinand de Saussure sobre a linguística geral". Depois, em 2002, é publicado por Simon Bouquet e Rudolf Engler o Escritos de Linguística Geral, traduzido no Brasil em 2004.

13 "Da essência dupla/a notar"; "Da essência dupla"; "Da dupla essência da (linguagem)". 
Uma edição crítica dos Escritos é publicada em 2011, pela editora Droz, em Genebra, ainda sem tradução brasileira. Seu editor, René Amacker (2011), um dos primeiros pesquisadores a tomar conhecimento dos documentos encontrados em 1996, insatisfeito com o trabalho realizado por Bouquet e Engler (cf. SAUSSURE, 2004 [2002]), lança esse novo trabalho. O título escolhido procura acolher as variadas anotações de Saussure no arquivo de que falamos: Science du langage: de la double essence du langage. Édition des Écrits de linguistique générale.

A edição, preparada então sob novas condições, até mesmo com inclusão de novos itens e levando em consideração as edições alemã e italiana, passou a representar um instrumento de trabalho mais rico e mais seguro para os estudiosos. "Graças a uma contextualização pensada com maturidade, cada fragmento se encontra assim esclarecido por seus vizinhos" (BÉGUELIN, 2016, p. 129-130).

Dadas as qualidades estruturais e filológicas da nova versão, trabalharemos no trecho a seguir com a transcrição de Amacker (2011), traduzindo-a ${ }^{14}$. Ao apresentar as convenções seguidas na edição, o linguista segue os critérios editoriais elaborados por Marchese (1995) e parte do princípio de que o texto deve ser "legivel sem esforço". Todas as indicações sobre a sua constituição são dadas em notas, salvo os seguintes indicadores: '[' (seguido de um fim de linha) = texto inacabado; '[ ]' = lacuna deixada pelo autor no texto; '<...> = integração necessária (palavra acrescida ou eventualmente palavra completada pelo editor). De nossa parte, recorreremos às notas de rodapé, quando necessário.

O manuscrito Ciência da linguagem inclui vários fragmentos que abordam a questão da identidade linguística, mas pela pertinência às nossas indagações e propostas em debate, tomamos do manuscrito 372 o fragmento 41 [2.12-14]. Trata-se de um documento extenso em que Saussure extrai as consequências teóricas e epistemológicas de um projeto de estudo sobre a identidade linguística que contemple sincronia e diacronia. Há tanto uma reflexão sobre o momento em que se encontra o trabalho investigativo, assim como o encaminhamento dos expedientes necessários dali para a frente, sem deixar de exprimir seu ceticismo sobre o futuro.

[2.14] No canto superior do manuscrito, está a nota l: "ler na ordem 14-13-12". I Ponto de vista do estado de língua em si mesmo.

Não diferente do ponto de vista instantâneo.

Não diferente do ponto de vista voluntariamente anti-histórico.

Não diferente do ponto de vista semiológico (ou do ponto de vista signo-ideia).

Não diferente do ponto de vista morfológico ou gramatical.

Não diferente dos elementos combinados.

As identidades nesse domínio são fixadas pela relação da significação e do signo, ou pela relação dos signos entre eles, o que não é diferente.

II Ponto de vista das identidades transversais.

Não diferente do ponto de vista diacrônico.

Não diferente do ponto de vista fonético (ou da figura vocal separada da ideia e separada da função de signo, o que é a mesma coisa em virtude de I).

Não diferente também do ponto de vista dos elementos isolados.

14 Nos Escritos de Linguística Geral, o excerto escolhido está nas páginas 24 e 25. 
III Ponto de vista cientificamente artificial $^{15}$

(As identidades desse domínio são dadas, antes de tudo, necessariamente por aquelas do precedente; mas depois disso elas se tornam a segunda ordem de identidades linguísticas, irredutivel à precedente).

[2.13] III Ponto de vista artificial, voluntário, e puramente didático da PROJEÇÃO de uma morfologia (ou de um "estado de língua" antigo) sobre uma morfologia (ou sobre um outro "estado de língua" posterior).

(O meio pelo qual pode-se operar essa projeção é a consideração das identidades transversais, II, combinada à consideração morfológica do primeiro estado, conforme I).

Não diferente do ponto de vista ANACRÔNICO \{RETROSPECTIVO\}.

Este ponto de vista é o ponto de vista ETIMOLÓGICO, compreendendo outras coisas além do que chamamos comumente de etimologia. Uma de suas características em relação a IV é de não levar em conta a época B em si mesma. ${ }^{16}$

IV Ponto de vista HISTÓRICO da fixação de dois estados de língua sucessivos tomados cada um em si mesmo, em primeiro lugar, e sem subordinação de um ao outro, seguido de explicação ${ }^{17}$

[2.14, margem superior] I e II resultam da natureza dos próprios fatos de linguagem.

[2.14, margem superior] III e IV resultam das maneiras legítimas de considerar ${ }^{18}$ [2.12] Desses quatro pontos de vista legitimos (além dos quais confessamos nada reconhecer), quase que só o segundo e o terceiro são cultivados. De fato, o quarto só poderá sê-lo proveitosamente no dia em que o primeiro... ${ }^{19}$

Em compensação, é vivamente cultivada a confusão lamentável entre esses diferentes pontos de vista, até mesmo nas obras sustentando as mais altas pretensões científicas. Há, certamente, com muita frequência, uma verdadeira ausência de reflexão por parte dos autores. Mas acrescentemos desde já uma profissão de fé: assim como estamos convencidos, com ou sem razão, que finalmente será preciso chegar ao ponto de tudo reduzir, teoricamente, aos nossos quatro pontos de vista legitimos repousando sobre dois pontos de vista necessários, assim também duvidamos que venha a ser possivel estabelecer, com pureza, a quádrupla ou somente a dupla terminologia que seria necessária (AMACKER, 2011, p. 94-97).

Este manuscrito, na sua transcrição rigorosa, mostra toda a complexidade de uma operação que vise discernir a identidade de um objeto que serve de signo. Além da minuciosa apresentação de cada ponto de vista e seu escopo de atuação nessa operação, Saussure procura traçar as linhas de relação entre os pontos de vista - todos legítimos -, mas nem todos presentes na quádrupla ou, quando presentes, os autores que se empenharam nessa tarefa são duramente criticados. Se quase sempre só o segundo e o terceiro são cultivados, Saussure não deixa de mencionar a relação necessária entre o quarto e o primeiro ponto

\footnotetext{
15 Item que ainda diz respeito a II, mas acompanhamos a disposição da transcrição de Amacker. Na edição dos Escritos não há o algarismo romano.

16 Nota de Amacker: esta última frase é um acréscimo parcialmente interlinear, provavelmente posterior à redação do ponto IV.

17 Nota de Amacker: duas linhas e meia em branco.

18 Nota de Amacker: essas adições (posteriores, na minha opinião, ao resto do texto), anotadas no alto das páginas 13 e 14 , resumem o exposto ao mesmo tempo que poderiam servir de baliza para os desenvolvimentos previstos, mas não redigidos.

19 Nota de Amacker: há uma linha e meia em branco. Os pontos estão afastados uns dos outros.
} 
de vista, mas essa dependência não chega a ser totalmente explicitada: "[...] de fato, o quarto só poderá sê-lo (cultivado) no dia em que o primeiro [...]".

Seguem duas linhas em branco antes do novo parágrafo. O branco do texto não deixa de ecoar as palavras de De Mauro sobre o pensamento de Saussure a respeito do problema da identidade no eixo diacrônico tal como foi relatado na primeira parte deste trabalho. Entretanto, agora não se trata mais da diacronia - de identificar o francês chaud ao latim calidus -, a situação é outra: no ponto de vista histórico, inicialmente, dois estados de lingua sucessivos - dois sistemas - são tomados cada um em si mesmo, sem subordinação de um ao outro, "seguido de explicação [".

E mais uma vez seguem duas linhas e meia em branco. Se o ponto de vista I é de algum modo essencial na relação com o IV - isto é, para que o IV seja cultivado -, a tarefa de explicitar essa relação, ainda que necessária, não era formulável nos seus termos.

Na sua "profissão de fé", Saussure enfrenta sem ilusão a tarefa do linguista ao abordar o seu objeto: declara ter certeza do que deve ser feito e, na mesma medida, duvida que se possa fazê-lo.

À complexidade da identidade linguística, considerada a partir dos pontos de vista, acresce-se outra quando o mestre se volta para a perspectiva da identidade do signo e de sua contraparte, a diferença.

Retomamos neste momento o episódio em que Saussure, ao tratar das diferentes ocorrências da palavra Senhores em uma conferência, afirma que o sentimento de identidade persiste apesar das diferenças fônicas facilmente reconhecíveis e conclui com um axioma: "O mecanismo linguístico gira todo ele sobre identidades e diferenças, não sendo estas mais que a contraparte daquelas" (SAUSSURE, 2018 [1916], p. 154). A identidade é, nesse caso, assegurada pelo mesmo valor. Por outro lado, em "son violon a le même son" ${ }^{20}$, a homofonia não é suficiente como critério de identidade. Os signos homófonos não são idênticos se os valores são diferentes.

O termo diferença na formulação saussuriana merece atenção. Se na relação entre identidades e diferenças estas não são mais do que a contraparte das identidades, qual o modo de relação entre esses dois termos na teorização saussuriana?

Jean Claude Milner (2002), em uma leitura sobre o conceito de diferença no CLG, mostra em que medida o pensamento saussuriano rompe com as concepções então sustentadas pela filosofia. Acompanhamos Milner.

A lógica escolástica já distinguia entre o próprio e a diferença e, de acordo com Edmond Globot (1901, p. 408):

O próprio é uma característica que pertence a uma espécie ou indivíduo, e não se encontra em nenhuma outra espécie ou individuo do mesmo gênero. O próprio é, portanto, suficiente para caracterizar a espécie. Entretanto, o distinguimos da diferença. A diferença é uma característica ao mesmo tempo própria e essencial. Uma característica essencial é permanente, ao passo que o próprio pode ser acidental ou passageiro.

É a partir dessa distinção que Milner encaminha sua reflexão sobre a diferença no CLG. Ao afirmar que "na língua só existem diferenças" (SAUSSURE, 2018 [1916], p. 167), Saussure assume que as entidades linguísticas devem reter

20 "Seu violão tem o mesmo som". A homofonia só pode ser escutada em francês. 
apenas as características próprias e essenciais. A ilustração escolhida é dada pela fonologia de Troubetzkoy: "do fonema, só se retém entre os traços próprios, os traços essenciais (as diferenças)" (MILNER, 2002, p. 36).

Para compreender todo o alcance da palavra diferença, é preciso acompanhar Saussure na continuidade do pequeno trecho citado há pouco, quando a questão do negativo vem se acrescentar ao que se disse sobre a diferença: "na língua só existem diferenças. E mais ainda: uma diferença supõe em geral termos positivos entre os quais ela se estabelece; mas na lingua há apenas diferenças sem termos positivos" (SAUSSURE, 2018 [1916], p. 167). Como observa Milner, é aí que a diferença em linguística "acrescenta à diferença clássica sua própria diferença específica” (MILNER, 2002, p. 36).

Para designar esse modo de funcionamento linguístico específico, Saussure propõe o nome de valor, que concebemos como o ponto de soldagem entre as identidades e as diferenças como sua contraparte, pois se o valor é o lugar da identidade sincrônica, é também o valor que determina o jogo das diferenças entre os termos que "seriam vazios e indeterminados sem essas diferenças" (SAUSSURE, 2004, p. 60).

Eis ainda por que as identidades são formuladas como uma complicação fecunda das entidades e das unidades. A teorização saussuriana sobre identidades e diferenças introduziu um novo tipo de entidades; se antes, na filosofia, "ser e ser um, eram propriedades ligadas" (MILNER, 2002, p. 37), para Saussure "nada é, pelo menos nada é absolutamente (no dominio linguístico)" (SAUSSURE, 2004, p. 74).

A entidade linguística como Saussure a define só existe pelas suas diferenças, sendo assim atravessada por todas as outras entidades da lingua, e a unicidade não é mais uma unicidade centrada em torno de um ponto íntimo de identidade a si; ela passa a ser definida pelo "entrecruzamento de determinações múltiplas" (MILNER, 2002, p. 37).

Conhecemos a novidade saussuriana: uma entidade pode permanecer idêntica mesmo se sua substância material mudou (como o caso das variações da palavra Senhores) e, inversamente, é possivel ver mudar a identidade de uma entidade cuja substância material permanece a mesma (como os casos de homofonia, com valores diferentes).

Saussure estava ciente dos passos que deu em direção à ruptura com a tradição filosófica; sua tese pode ser resumida pela fórmula "há disjunção entre identidade e semelhança" (MILNER, 2002, p. 38).

Acompanhamos, para encerrar, a conclusão de Milner sobre o alcance do movimento gerado pelo pensamento saussuriano, que afetou o panorama das ciências humanas, da cultura, da psicanálise à filosofia.

Não se pode imaginar ruptura mais profunda do ponto de vista da tradição filosófica. Quer seja ela idealista ou empirista, esta última com certeza distinguiu radicalmente entre identidade e semelhança. Mas admitia-se que uma relação devia subsistir entre as duas: que a semelhança material era um índice - eventualmente enganador, mas sempre digno de consideração - de identidade; que a identidade acontecia de certo modo naturalmente pelas semelhanças. Daqui por diante, a relação está rompida. Pode-se adiantar que todo o Curso se propõe a resolver o problema que foi assim formulado. O estruturalismo generalizado, no que ele tinha de melhor, consistiu em levar a sério essa solução, para explorar 
as diversas possibilidades. Tomado em extensão, o programa poderia se aplicar a toda espécie de realidade, se se admite (hipótese estruturalista forte) que toda realidade pode ser considerada do único ponto de vista de suas relações sistêmicas. Levado ao seu limite extremo, ele conduzia a um novo tipo de ontologia (MILNER, 2002, p. 38).

\section{What does Linguistic IDENTITy Consist of? A SAUSSUREAN guestion}

Abstract: This work proposes a reflection on the Saussurean concept of linguistic identity. The Analytical Index of the Cours de Linguistique Générale (2018 [1916]) shows us that the term identity receives only two entries: a chapter on synchronic identity and another on diachronic identity. Those two topics, however, open up a universe of great theoretical scope. With the help of other sources of consultation, our objective is to reflect on the paths pointed out by Saussure to face the problem of linguistic identity, namely, the issue of the point of view and the consideration of an entity type that breaks up with the philosophical tradition.

Keywords: Identity. Difference. Value. Point of view. Synchrony/diachrony.

\section{REFERÊNCIAS}

AMACKER, R. Science du langage: de la double essence du langage. Genève: Librairie Droz, 2011.

BACON, F. The philosophical works of Francis Bacon. New York, 2011 [1905].

BÉGUELIN, M. J. Opérer hors de toute étymologie. La diachronie dans L'Essence double de Ferdinand de Saussure. In: RASTIER, F. De l'essence double et le renouveau du saussurisme. Limoges: Lambert-Lucas, 2016. p. 123-143.

GODEL, R. Les sources manuscrites du Cours de Linguistique Générale de F. de Saussure. Genève: Librairie Droz, 1969.

GLOBOT, E. Le vocabulaire philosophique. Paris: Armand Colin, 1901.

MARCHESE, M. P. Ferdinand de Saussure. Phonétique. Il manoscritto di Harvard Houghton Library bMS Fr 266(8). Firenze: Unipress, 1995.

MILNER, J. C. Le périple structural: figures et paradigme. Paris: Seuil, 2002.

SAUSSURE, F. Ms. fr. 3951, fol. 1v. Bibliothèque de Genève, 1894.

SAUSSURE, F. Cours de Linguistique Générale. Édition critique par Rudolf Engler. Wiesbaden: Otto Harrassowitz, 1989 [1968].

SAUSSURE, F. Deuxième cours de linguistique générale (1908-1909). Cahiers de A. Riedlinger e C. Patois. Oxford: Pergamon Press, 1997.

SAUSSURE, F. Escritos de Linguistica Geral. São Paulo: Cultrix, 2004.

SAUSSURE, F. Cours de Linguistique Générale. Édition critique par Tullio De Mauro. Paris: Payot, 2005 [1967].

SAUSSURE, F. Curso de Linguística Geral. São Paulo: Cultrix, 2018 [1916].

SAUSSURE, F. Troisième cours de linguistique général (1910-1911). Cahiers d'Emile Constantin. Oxford: Pergamon Press, 1993. 
DOSSIÊ

TURRA, M. B. Ferdinand de Saussure e seu saber fazer com a escrita, ou do que se circunscreve de um enigma. 2018. 205 f. Tese (Doutorado em Linguística) Universidade Estadual de Campinas, Campinas, 2018.

\begin{abstract}
Anexo
Autorização do uso do manuscrito:

Nous vous autorisons volontiers à publier cet extrait de notes de linguistique de Ferdinand de Saussure. Nous vous prions de mentionner la source de l'image de la manière suivante: Genève, Bibliothèque de Genève, Ms. fr. 3951, fol. $1 v$.

Vous pouvez vous adresser à notre service de reprographie si vous avez besoin d'une image au format tiff. Je leur transmettrai le cas échéant votre demande. En vous souhaitant franc succès dans votre publication, je vous adresse mes meilleures salutations.
\end{abstract}

Paule Hochuli Dubuis

Conservatrice

BIBLIOTHÈQUE

DE GENÈVE

Département des manuscrits

mss.bge@ville-ge.ch 